Title: Sexuality and sexual health among female youth with borderline personality disorder pathology

Authors: Dr Katherine N Thompson, $\mathrm{PhD}^{1,2}$

\author{
Dr Jennifer Betts, D.Psych ${ }^{1,2}$ \\ Dr Martina Jovev, $\mathrm{PhD}^{1,2,3}$ \\ Dr Yolanda Nyathi, MBBS ${ }^{1}$ \\ Dr Emma McDougall, D.Psych ${ }^{1}$ \\ Prof Andrew M Chanen, MBBS; PhD; FRANZCP 1,2,3
}

\begin{abstract}
Affiliation:
${ }^{1}$ Orygen, The National Centre of Excellence in Youth Mental Health;

${ }^{2}$ Centre for Youth Mental Health, The University of Melbourne;

${ }^{3}$ Orygen Youth Health
\end{abstract}

Corresponding author: Prof Andrew Chanen

Orygen, the National Centre of Excellence in Youth Mental Health

Locked Bag 10, Parkville, Victoria 3052, Australia.

E-mail: andrew.chanen@orygen.org.au

This is the author manuscript accepted for publication and has undergone full peer review but has not been through the copyediting, typesetting, pagination and proofreading process, which may lead to differences between this version and the Version of Record. Please cite this article as doi: 10.1111/eip.12510

This article is protected by copyright. All rights reserved. 
Acknowledgements: The authors would like to acknowledge the valuable assistance of Prof Marian Pitts and the late Prof Anthony Smith from the Australian Research Centre in Sex, Health and Society, La Trobe University, Melbourne, Australia, for collaboration in the design of the study and in providing data from the Australian Study of Health and Relationships.

Disclosure Statement: The Australian Study of Health and Relationships was funded by a National Health and Medical Research Centre project grant. Collection of BPD patient data, and analyses of findings were unfunded.

Conflict of Interest: The authors have no conflict of interest to declare.

Article Type: Original Article

Word Count:3122 words; abstract 250 words ( $<3000$; abstract $<250$ words)

Please note that the word count has been exceeded in order to adequately address the reviewers comments.

Tables: 3 


\begin{abstract}
Aim: Borderline personality disorder (BPD) is a severe mental disorder that is characterized by unstable relationships, impulsive behaviours and identity disturbance. BPD usually has its onset between puberty and young adulthood and presents disproportionately among females in clinical settings. Taken together, this makes young women with BPD a particularly vulnerable group with regard to healthy psychosexual development. It was hypothesized that female youth with BPD pathology would be more likely to score worse on measures of sexual health and safety, and to show greater uncertainty in sexual identity formation.
\end{abstract}

Methods: Fifty 15-24 year-old females with three or more DSM-IV BPD criteria were compared with 204 females from a nationally representative sample. Both groups were interviewed using a comprehensive interview for sexual health and relationships. The patient group completed a structured diagnostic interview.

Results: Young women with borderline personality pathology engaged in sexual relationships at a younger age, with more sexual partners in the previous year, in more casual relationships. They were more likely to practice unsafe sex for their first sexual experience, to be coerced into unwanted sexual activity, to be unclear about their sexual identity or their sexual attraction, and to report worse overall health status.

Conclusions: BPD pathology in youth is associated with poor sexual health and safety, and uncertainty in sexual identity formation. These findings support the need for assessment of the sexuality and sexual health of youth with BPD, along with the need for routine screening in sexual health services for BPD features among high- 
risk youth.

Key Words: borderline personality disorder, sexual identity, sexuality, impulsivity, relationships, sexually transmitted infections. 


\section{Sexuality and sexual health among female youth with borderline personality disorder pathology}

\section{Introduction}

Borderline personality disorder (BPD) is a severe mental disorder that is characterized by a pervasive pattern of instability in emotional regulation, interpersonal relationships and self-image, along with marked impulsivity ${ }^{1}$. BPD has a fourfold higher prevalence among primary care patients than among the general population ${ }^{2}$ and affects around one in five psychiatric outpatients ${ }^{3}$.

There are limited empirical data on the sexuality (sexual attraction, behaviour, or identity) of patients with BPD, and several features of the disorder are likely to be associated with problematic sexual health, such as self-damaging impulsivity (impulsive sexual behaviour), identity disturbance (unstable sexual identity), and unstable and intense interpersonal relationships that might involve costly relationship tactics in an attempt to retain a mate (impulsive and risky sexual behaviour that might expose them to coercion and abuse) ${ }^{4}$. Moreover, childhood and adult sexual violence and abuse are common among the histories of individuals with BPD ${ }^{5}$. Even less is known about this topic among those with sub-threshold features of the disorder, or at the time of illness onset, between puberty and young adulthood, when preventive measures might be most effective ${ }^{6}$. This study is the first to comprehensively assess sexuality and sexual health in youth with BPD pathology, and to compare this group with a representative community sample.

Adults with BPD report more sexual relationship difficulties ${ }^{7}$, are more likely to engage in impulsive sexual activity ${ }^{8}$, have an earlier age of onset for sexual 
intercourse, experience victimisation from date rape ${ }^{9}$, have more sexual partners ${ }^{10}$ ${ }^{11}$, a greater risk of sexually transmitted infections (STIs), and pregnancy risk from poor use of contraception compared to primary care or psychiatric patients ${ }^{10}$. They are more likely to be coerced into having sex ${ }^{12}$, and to have impaired sexual function ${ }^{13}$. Sexual health is further adversely impacted by a diagnosis of BPD and co-occurring substance use disorder, as indicated by even higher rates of STIs ${ }^{14}$, and unprotected sex ${ }^{15}$. Adults with BPD are more likely to identify as homosexual or bisexual, and to report a change in gender of their sexual partner regardless of comparison group ${ }^{16,17}$.

In contrast to these studies, little is known about the sexual health and relationships of young people with BPD. Adolescents with BPD have been reported to experience romantic relationship dysfunction ${ }^{18}$, and to be more likely to have a current sexual partner, to be sexually active, and to have higher lifetime rates of STIs 19. In a community sample of adolescents, those with BPD were found to have a greater percentage of sexual minorities (40\%) compared with a non-BPD group $(17 \%)^{20}$. Sexual minority identity was associated with a greater number of BPD features, with adolescents who showed lower clarity of sexual identity as reporting greater BPD features than those who identified as homosexual or heterosexual ${ }^{20}$. The combination of depression, anxiety and sexual orientation was found to predict BPD features ${ }^{20}$. These studies provide some important information about adolescent sexual development and how BPD features might be related to sexual behaviour, sexual selfhood, sexual socialization, and sexual identity integration ${ }^{20,21}$.

This study builds upon earlier research regarding sexual activity in young patients with BPD ${ }^{19}$. It aims to investigate aspects of the sexuality and sexual health 
among female youth (aged 15-24 years) with BPD pathology (including subsyndromal BPD, i.e. 3-9 criteria), and to compare this with a matched healthy population sample. Compared with female youth from the Australian community, it was hypothesized that female youth with BPD pathology would score worse on measures of sexual health, risk and safety, and that they would show greater indecision in their sexual identity formation.

\section{Methods}

Participants

The BPD group comprised 50 female youth. They attended a governmentfunded, specialized early intervention program for BPD in Melbourne, Australia, that includes patients aged 15-24 years with at least three DSM-IV/DSM-5 BPD criteria ${ }^{22}$. Although historically conceptualised as a categorical diagnosis ${ }^{23}$, there is strong evidence indicating that BPD is in fact a dimensional construct ${ }^{24}$ and the rationale for intervention for sub-syndromal (indicated prevention) and full-syndrome (early intervention) BPD has been described elsewhere 2225 .

All BPD participants (or a parent/guardian if $<18$ years old), provided written informed consent. Participants were reimbursed for time and expenses. The Melbourne Health Human Research and Ethics Committee approved this study.

BPD group data were compared with population data collected from the Australian Study of Health and Relationships (ASHR), which has been described elsewhere ${ }^{26}$. This Australia-wide telephone survey included a total of 3469 people, 
aged 16-64 years. Participants completed a computer-assisted telephone interview that took approximately 25 minutes to complete.

Survey data were matched with patient information according to age (i.e., 1624 years), geographical location within the Melbourne metropolitan region, and sex (female). Geographical region is used by the Australian Bureau of Statistics as an indicator of socioeconomic status ${ }^{27}$. Data were extracted for a total of 204 women for the comparison group. The mean age of the total sample was 20.33 years (SD 2.71, $n=254$ ), of which 58 were aged 15-17 years (M 16.66; SD 1.19), and 196 were aged 18-24 years (M21.42; SD 2.00). The BPD and comparison groups did not significantly differ in their marital status $\left(x^{2}=5.35, d f=2, p=0.069\right)$ but did differ significantly in several demographic variables. The BPD group was more likely to have been born in Australia $\left(x^{2}=7.22, d f=1, p=0.007\right)$, less likely to live with a husband/partner $\left(x^{2}=4.30, d f=1, p=0.038\right)$, and more likely to live with someone other than a family member $\left(x^{2}=6.24, \mathrm{df}=1, p=0.013\right)$. They had a lower level of education $\left(\mathrm{X}^{2}=12.56, \mathrm{df}=5, p=0.028\right)$, and were more likely to be unemployed or had a lower occupational status $\left(\mathrm{x}^{2}=31.78, \mathrm{df}=5, p<0.0005\right)$.

Among the BPD group, nine participants (18\%) had three DSM-IV BPD criteria, $10(20 \%)$ had four, $13(26 \%)$ had five, nine (18\%) had six, five $(10 \%)$ had seven, and four (8\%) had eight. Ninety-two percent also had one co-occurring DSMIV mental state (Axis I) disorder, $70 \%$ had two, 52\% had three, $36 \%$ had four, and $12 \%$ had five. Current DSM-IV mental state disorder diagnoses included: major depressive disorder (62.0\%), dysthymic disorder (22.0\%), bipolar disorder (10.0\%), anxiety disorder (100.0\%), posttraumatic stress disorder (30.0\%), conduct disorder $(6.0 \%)$, substance dependence/abuse $(14.0 \%)$, eating disorder $(14.0 \%)$, psychotic 
disorder $(2.0 \%)$, other $(2.0 \%)$.

\section{Measures}

This study used the ASHR Health and Relationships Questionnaire ${ }^{26,28,29}$, which comprehensively measured aspects of sexual health and behaviour, together with general health, substance use, and psychological well being (Kessler 6 Psychological Distress Scale) ${ }^{30}$. Self-reported health score was rated $1=$ excellent through $5=$ poor. Total Kessler 6 score was the sum of items, which were rated 1=all the time through $5=$ none of the time.

The patient group was assessed using the Structured Clinical Interview for DSM-IV Axis I disorders (SCID-I/P) ${ }^{31}$ and the BPD module of the Structured Clinical Interview for DSM-IV Axis II disorders (SCID-II) ${ }^{32}$.

\section{Analyses}

K6 scores were recoded so that $0=$ none of the time and $4=$ all of the time. Categorical variables were analysed using Chi-Square non-parametric tests. All other comparisons were made using independent t-tests. These tests were corrected using Bonferroni adjustment to reduce the chance of a Type I error.

\section{Results}

First sexual experience

The BPD pathology group was significantly more likely to engage in sexual activity at a younger age than their peers (Table 1). There was no significant difference between the BPD group and controls in the length of time they had known 
their partner before engaging in sex for the first time. The BPD group was more likely to use no form of contraception ( $n=12 / 38,31.6 \%$ ), whereas controls mostly used a condom $(n=110 / 155,71.0 \%)\left(x^{2}=27.48, d f=4, p<0.0005\right)$. For this first sexual experience, $31.5 \%$ of BPD group used no contraception compared with $22.6 \%$ of controls, and did not use a combination of condom and oral contraceptive (BPD 0\%, control 13.5\%), but tended to use only a condom (BPD 68.4\%, control $71.0 \%)\left(\mathrm{X}^{2}\right.$ $=27.48, \mathrm{df}=4, p=<0.0005)$.

\section{Number of sexual partners}

The BPD group engaged in oral sex with significantly more men in their lifetime. They had a greater number of male partners with whom they had sexual intercourse, or oral sex within the previous 12-month period (Table 1).

\section{Current sexual relationship}

The BPD group was significantly more likely to be in a casual relationship ( $n=16 / 39,41.0 \%)$, compared with controls who engaged in steady relationships $(n=123 / 155,79.4 \%)\left(x^{2}=14.42, d f=4, p=0.006\right)$. Of those participants who were in a current relationship, those in the BPD group had been in that relationship for significantly more months $(p=0.007)$. The BPD group was significantly more likely to

use contraception in their current relationship (BPD 68.4\%, control 44.2\%; $x^{2}=4.60$, $\mathrm{df}=1, p<0.032$ ). There was no significant difference in the amount of physical pleasure reported. However, the BPD group reported significantly less emotional satisfaction in their relationship $\left(x^{2}=11.16, d f=4, p=0.025\right)$.

\section{[INSERT TABLE 1]}


Sexual Coercion

The BPD group was more likely to be coerced into having sex (Table 2). They were significantly more likely to have been forced more times to engage in sexual activity they did not want $(\mathrm{t}=-0.24, \mathrm{df}=27.86, p=0.023)$. There was no significant difference in the age at which each group was first coerced $(t=0.54, d f=42, p=0.591$ ).

\section{[INSERT TABLE 2]}

Health

The BPD group had a significantly worse (higher) mean general health score than the controls (Table 3), and significantly greater psychological distress (K6 score). The BPD group had significantly higher levels of smoking. They drank less frequently than controls, but tended to drink significantly greater amounts. While the BPD group tended toward having their first pregnancy at a younger age together with a higher rate of terminations, these differences were not statistically significant. Rates were similar for pubic lice, genital warts, wart virus (HPV), genital herpes, syphilis, gonorrhoea, gardnerella, and trichomoniasis, Hepatitis A, B and C. The one exception being that the BPD group had a significantly higher incidence of Candida/Thrush $\left(x^{2}=6.23, \mathrm{df}=1, p=0.013\right)$.

\section{[INSERT TABLE 3]}

\section{Sexual identity}

The BPD group significantly differed in terms of their sexual identity, sexual attraction and sexual experience $\left(x^{2}=43.49, \mathrm{df}=3, p<0.0005 ; x^{2}=29.07, \mathrm{df}=5\right.$, $\left.p<0.0005 ; X^{2}=22.85, d f=5, p<0.0005\right)$. More of the BPD group identified as being 
attracted to both sexes (BPD 18\%, control 4.4\%), or same sex attracted (BPD 8\%, control 1\%), or were undecided about their sexual orientation (BPD 10\%, control $0 \%$ ). The BPD group was less likely to be only or mostly attracted to males (BPD pathology $82 \%$, control $95.6 \%$ ). Ten percent of the BPD group reported being attracted to both sexes equally, and $8 \%$ were mostly or only attracted to females. In terms of sexual experience, the majority of both groups had mostly or only opposite sex experience (BPD 86\%, control 88.2\%), but controls were more likely to have had no experience (BPD 2\%, control 9.9\%), and more of the BPD group reported equal experience (BPD $6 \%$, control $0.5 \%$ ) or mostly, or only, same sex experience (BPD $6 \%$, control $1.5 \%)$.

\section{Discussion}

Female youth with BPD pathology were more likely to score poorly on measures of sexual health, risk and safety, and showed greater indecision in their sexual identity formation. These findings are consistent to those in adults, except with regard to rates of STIs. They suggest the sexual health and relationships of female youth with BPD pathology differs from that of their community peers, and on some variables, these differences are likely to be associated with clinically important adverse consequences.

The core BPD pathology features of unstable interpersonal relationships and impulsivity are evidenced in the young women in this study who engaged in sexual activity at an earlier age, with less protection, and with more partners and in the context of more casual relationships. They engaged in oral sex with significantly more men in their lifetime, and had a greater number of sexual partners over the 
past 12-months. These findings are comparable with those reported in studies of adults with BPD ${ }^{8-11,18,19,33}$. The young women in our sample also tended to engage in sexual behaviour with other females at a much younger age, compared with their community peers, although this is a curious finding that warrants cautious interpretation due to the low number of responses to this survey item. A key clinical implication of these findings is potential exposure to STIs, unplanned pregnancy, coercion and/or sexual assault.

Earlier initiation of sexual activity is associated with increased risk for STIs ${ }^{19}$, ${ }^{34,35}$, but this was not evident in the current findings. This stands in contrast to findings from an earlier study ${ }^{19}$ and might be due to the use of a more robust interview measure for STIs in this study. The low STI rate might also be related to assessing this relatively early in the sex lives of these young people, and/or the absence of an objective biological measure. For example, chlamydia trachomatis is common among Australian women aged 16 to 25 years and a high proportion of women are re-infected within a short period of time ${ }^{36,37}$, but this was not detected in the current study.

It is of interest that these young women were less likely to use contraception or a combination of oral contraception plus condom during their first sexual experience than controls, but they were more likely to use contraception for their current relationship. It might be that precocious sexual behaviour in this group is associated with earlier, adaptive use of contraception. However, this finding, along with the relative lack of difference in the number of STIs in these patients, compared with community peers, might also reflect the exposure of these young women to specialized care for BPD at an early intervention service ${ }^{38}$, where sexual history 
taking is routine and contraception and safe sex are commonly part of early psychoeducation. It lends support to the importance of providing early detection and intervention for young people with $\mathrm{BPD}^{25}$ as a means of preventing a diverse array of adverse longer term outcomes, such as unplanned pregnancy and STIs.

It is noteworthy that young women with BPD pathology were more likely to be in a relationship at the time of interview, compared with their community peers. While they reported similar levels of physical pleasure from these relationships, they reported significantly lower levels of emotional satisfaction. This might reflect the tumultuous nature of their intimate relationships or simply their casual nature and lack of emotional investment. Alternatively, it is possible that this finding reflects the poor social cognition and impaired problem solving skills of this group ${ }^{39}$ and might relate to their preference to engage in sexual behaviour to retain their partner ${ }^{4}$.

Young women with BPD pathology were significantly more likely to be coerced into unwanted sexual experiences, and forced or frightened into engaging in sexual acts. This finding has been reported in adults with BPD ${ }^{10,33,40}$ and many patients with BPD have a past history of sexual abuse or rape. These findings suggest that these problems continue from youth into adulthood. Among young women with BPD pathology, sexual coercion and sexual assault constitute important clinical problems that require active clinical enquiry and well-defined management. An additional consideration is that many individuals will experience subsequent sexual relationship difficulties ${ }^{7}$ and for some, engaging in a sexual relationship will provoke trauma-related symptoms ${ }^{10}$. This might eventually lead women with BPD to avoid sexual relationships ${ }^{10,13}$. 
Identity disturbance, defined as markedly and persistently unstable self-image or sense of self, is a core feature of BPD and this was evident in the number of young women who remained undecided about their sexual identity, sexual attraction, and whether they prefer to engage in sexual experiences with just males or females, or both. This replicates findings in a study of adolescents, which reported that BPD features were associated with greater uncertainty regarding sexual identity, compared with same-age peers ${ }^{20}$. These findings are similar to those reported in adults with BPD, who experienced a fluidity of sexual partners ${ }^{41,17}$. However it does not follow that people who identify as being non-heterosexual are more likely to have BPD $^{42}$. Based on other studies, sexual orientation contributes to BPD features over and above depression, anxiety ${ }^{20}$. A possible mechanism for this relationship is a minority stress model, where having a sexual identity that is less common exposes the young person to invalidation, and this in turn might contribute to an inability to manage emotional experiences, i.e. emotional dysregulation ${ }^{20,43}$. This is one possible mechanism that might explain the interaction between sexual identity development and BPD features. Therefore, clinical services for young women with BPD pathology need to be sensitive to the diversity of sexual orientations and their changing nature, and to have a more specific focus upon assessing sexual identity formation and encouraging its healthy development.

Finally, the BPD group had a significantly worse (higher) mean general health score than controls. This is consistent with findings from clinical ${ }^{44,45}$ and communitybased studies ${ }^{46}$. In adults, BPD is specifically associated with a range of physical health problems, including cardiovascular disease, arthritis and gastrointestinal conditions. 
Strengths of the current study include the use of a nationally representative comparison group that was carefully matched according to age, sex and geographic location. Geographical location is important because it is used as an indicator of both socioeconomic status and education. The majority of the clinical data were collected within 3-4 years of the national population sample, minimizing the likelihood that secular trends in sexuality influenced the findings. BPD pathology was assessed in the clinical sample by highly trained researchers using a standard diagnostic DSMIV/DSM-5 interview.

Limitations to the study include significant differences in a number of demographic variables despite efforts to carefully match these groups, and the reliance on the K6 (rather than a SCID interview) to measure psychopathology in community peers. K6 was not used as a covariate in this sample due to the large number of missing data points for this variable in the ASHR community sample. Future studies could extend this work by using objective biological measures to detect STIs, by assessing gender identity more fully, and incorporating males with BPD pathology.

This is the first study to investigate the sexuality and sexual health of female youth with BPD pathology and compare the findings with a matched community sample. The findings indicate that the general pattern of sexuality and sexual health in adults with BPD is present early in the course of the disorder. Primary care, mental health, sexual health, and sexual assault service clinicians should be attuned to the clinical diagnosis of BPD because the nature of the disorder represents both a risk factor and a perpetuating factor for these issues. They should actively discuss and routinely assess issues like unsafe sex, STIs, sexual coercion, and sexual 
identity in youth with BPD pathology.

This article is protected by copyright. All rights reserved. 


\section{References}

1. Leichsenring F, Leibing E, Kruse J, New AS, Leweke F. Borderline personality disorder. The Lancet. 2011; 377: 74-84.

2. Gross R, Olfson M, Gameroff M, et al. Borderline personality disorder in primary care. Arch Intern Med. 2002; 162: 53-60.

3. Zimmerman M, Chelminski I, Young D. The frequency of personality disorders in psychiatric patients. The Psychiatric clinics of North America. 2008; 31: 405-20, vi. 4. Tragesser SL, Benfield, J. Borderline personality disorder features and mate retention tactics. Journal of Personality Disorders. 2012; 26: 334-44.

5. Zanarini MC, Frankenburg FR, Reich DB, Marino MF, Haynes MC, Gunderson JG. Violence in the lives of adult borderline patients. The Journal of nervous and mental disease. 1999; 187: 65-71.

6. Chanen AM, Thompson K. Preventive Strategies for Borderline Personality Disorder in Adolescents. Current Treatment Options in Psychiatry. 2014; 1: 358-68. 7. Zanarini MC, Parachini, E. A., Frankenburg, F. R., Holman, J. B., Hennen, J., Reich, D. B., Silk, K. R. Sexual relationship difficulties among borderline patients and axis II comparison subjects. Journal of Nervous and Mental Disease. 2003; 191: 479-82.

8. Sansone RA, Weiderman, M.W. Borderline personality symptomatology, casual sexual relationships, and promiscuity. Psychiatry. 2009; 6: 36-40.

9. Sansone RA, Barnes, J., Muennich, E., Wiederman, M.W. Borderline personality symptomatology and sexual impulsivity. International Journal of Psychiatry in Medicine. 2008; 38: 53-60.

10. Sansone RA, Lam, C., Wiederman, M. W. The relationship between 
borderline personality disorder and number of sexual partners. Journal of Personality Disorders. 2011; 25: 782-8.

11. Bouchard S, Godbout, N., Sabourin, S. Sexual attitudes and activities in women with borderline personality disorder involved in romantic relationships. Journal of Sex and Marital Therapy. 2009; 35: 106-21.

12. Sansone RA, Sansone, L. A. Sexual behavior in borderline personality: a review. Innovations in clinical neuroscience. 2011; 8: 14-8.

13. Schulte-Herbruggen O, Ahlers CJ, Kronsbein JM, et al. Impaired sexual function in patients with borderline personality disorder is determined by history of sexual abuse. The journal of sexual medicine. 2009; 6: 3356-63.

14. Chen EY, Brown MZ, Lo TT, Linehan MM. Sexually transmitted disease rates and high-risk sexual behaviors in borderline personality disorder versus borderline personality disorder with substance use disorder. The Journal of nervous and mental disease. 2007; 195: 125-9.

15. Harned MS, Pantalone DW, Ward-Ciesielski EF, Lynch TR, Linehan MM. The prevalence and correlates of sexual risk behaviors and sexually transmitted infections in outpatients with borderline personality disorder. The Journal of nervous and mental disease. 2011; 199: 832-8.

16. Bradford Reich D, Zanarini, M.C. Sexual orientation and relationship choice in borderline personality disorder over ten years of prospective follow-up. Journal of Personality Disorders. 2008; 22: 564-72.

17. Singh D, McMain S, Zucker KJ. Gender identity and sexual orientation in women with borderline personality disorder. The journal of sexual medicine. 2011; 8: 447-54. 
18. Selby EA, Braithwaite SR, Joiner TE, Fincham FD. Features of borderline personality disorder, perceived childhood emotional invalidation, and dysfunction within current romantic relationships. J Fam Psychol. 2008; 22: 885-93.

19. Chanen AM, Jovev M, Jackson HJ. Adaptive functioning and psychiatric symptoms in adolescents with borderline personality disorder. The Journal of clinical psychiatry. 2007; 68: 297-306.

20. Reuter TR, Sharp C, Kalpakci AH, Choi HJ, Temple JR. Sexual Orientation and Borderline Personality Disorder Features in a Community Sample of Adolescents. J Pers Disord. 2016; 30: 694-707.

21. Tolman DL, McClellend SI. Normative sexual development in adolescence: A decade in review 2000-2009. Journal of Research on Adolescence. 2011; 21: 24255.

22. Chanen AM, McCutcheon, L. K., Germano, D., Nistico, H., Jackson, H. J., McGorry, P. D. The HYPE Clinic: an early intervention service for borderline personality disorder. Journal of psychiatric practice. 2009; 15: 163-72.

23. APA. Diagnostic and Statistical Manual of Mental Disorders ( $5^{\text {th }}$ edition). Arlington, VA: American Psychiatric Publishing; 2013.

24. Zimmerman M, Chelminski I, Young D, Dalrymple K, Martinez J. Does the presence of one feature of borderline personality disorder have clinical significance? Implications for dimensional ratings of personality disorders. The Journal of clinical psychiatry. 2012; 73: 8-12.

25. Chanen AM, McCutcheon, L. Prevention and early intervention for borderline personality disorder: current status and recent evidence. British Journal of Psychiatry. 2013; 202: s24-s9. 
26. Smith AM, Pitts MK, Shelley JM, Richters J, Ferris J. The Australian longitudinal study of health and relationships. BMC Public Health. 2007; 7: 139.

27. ABS. Measures of socioeconomic status. ACT: Australian Bureau of Statistics; 2011 Contract No.: Document Number|.

28. Smith AMA, Patrick, K., Heywood, W., Pitts, M.K., Richters, J., Shelley, J.M., Simpson, J.M., Ryall, R. Sexual practices and the duration of last heterosexual encounter: Findings from the Australian longitudinal study of health and relationships. Journal of Sex Research. 2012; 49: 487-94.

29. Smith AMA, Lyons, A., Ferris, J.A., Richters, J., Pitts, M.K., Shelley, J.M., Simpson, J.M., Heywood, W., Patrick, K. Incidence and persistence/recurrence of women's sexual difficulties: Findings from the Australian longitudinal study of health and relationships. Journal of Sex and Marital Therapy. 2012; 38: 378-93.

30. Kessler RC, Andrews G, Colpe LJ, Hiripi E, Mroczek DK, Normand SL. Short screening scales to monitor population prevalences and trends in non-specific psychological distress. Psychological medicine. 2002; 32: 959-76.

31. First MB, Spitzer RL, Gibbon M, Williams JBW. Structured Clinical Interview for DSM-IV Axis I Disorders, Research Version, Non-patient Edition. (SCID-I/NP). New York: Biometrics Research, New York State Psychiatric Institute; 1996.

32. First MB, Gibbon M, Spitzer RL, Williams JBW, Benjamin LS. User's guide for the structured clinical interview for DSM-IV Axis II personality disorders.

Washington,DC: American Psychiatric Press; 1997.

33. Sansone RA, Chu JW, Wiederman MW. Sexual behaviour and borderline personality disorder among female psychiatric inpatients. Int J Psychiatry Clin Pract. 2011; 15: 69-73. 
34. Kaestle CE, Halpern CT, Miller WC, Ford CA. Young age at first sexual intercourse and sexually transmitted infections in adolescents and young adults. American journal of epidemiology. 2005; 161: 774-80.

35. Coker AL, Richter, D.L., Valois, R.F., McKeown, R.E., Garrison, C.Z., Vincent, M.L. Correlates and consequences of early initiation of sexual intercourse. Journal of School Health. 1994; 64: 372-7.

36. Walker J, Tabrizi SN, Fairley CK, et al. Chlamydia trachomatis incidence and re-infection among young women--behavioural and microbiological characteristics. PLoS One. 2012; 7: e37778.

37. Lewis D, Newton DC, Guy RJ, et al. The prevalence of Chlamydia trachomatis infection in Australia: a systematic review and meta-analysis. BMC infectious diseases. 2012; 12: 113.

38. Chanen AM, McCutcheon LK, Kerr IB. A cognitive analytic therapy based prevention and early intervention program for borderline personality disorder. In: CSharp C, Tackett JL, eds. Handbook of Borderline Personality Disorder in Children and Adolescents. New York: Springer; 2014.

39. Lazarus SA, Cheavens JS, Festa F, Zachary Rosenthal M. Interpersonal functioning in borderline personality disorder: a systematic review of behavioral and laboratory-based assessments. Clinical psychology review. 2014; 34: 193-205. 40. Sansone RA, Sansone, L. A. Gender patterns in borderline personality disorder. Innovations in clinical neuroscience. 2011; 8: 16-20.

41. Reich DB, Zanarini MC. Sexual orientation and relationship choice in borderline personality disorder over ten years of prospective follow-up. J Pers Disord. 2008; 22: 564-72. 
42. Eubanks-Carter C, Goldfried MR. The impact of client sexual orientation and gender on clinical judgments and diagnosis of borderline personality disorder. J Clin Psychol. 2006; 62: 751-70.

43. Crowell SE, Beauchaine TP, Linehan MM. A biosocial developmental model of borderline personality: Elaborating and extending Linehan's theory. Psychological bulletin. 2009; 135: 495-510.

44. Fok M, Hotopf M, Stewart R, Hatch S, Hayes R, Moran P. Personality disorder and self-rated health: a population-based cross-sectional survey. J Pers Disord. 2014; 28: 319-33.

45. Frankenburg FR, Zanarini MC. The association between borderline personality disorder and chronic medical illnesses, poor health-related lifestyle choices, and costly forms of health care utilization. The Journal of clinical psychiatry. 2004; 65: 1660-5.

46. Quirk SE, Berk M, Chanen AM, et al. Population prevalence of personality disorder and associations with physical health comorbidities and health care service utilization: A review. Personality disorders. 2016; 7: 136-46. 
Table 1

Age of onset of sexual activity, number of sexual partners, and length of current relationship

\begin{tabular}{|c|c|c|c|c|c|c|}
\hline Survey Item & Group & $\mathbf{N}$ & Mean & SD & $\mathbf{t}$ & $\mathbf{p}$ \\
\hline \multicolumn{7}{|l|}{ Sexual History } \\
\hline \multirow[t]{2}{*}{ Age when first had vaginal intercourse } & Control & 152 & 17.11 & 2.01 & 4.07 & $<.0005^{*}$ \\
\hline & BPD pathology & 39 & 15.60 & 2.30 & & \\
\hline \multirow[t]{2}{*}{ Age when first had oral sex with a male } & Control & 138 & 17.64 & 5.53 & 2.38 & .019 \\
\hline & BPD pathology & 34 & 15.35 & 1.97 & & \\
\hline \multirow[t]{2}{*}{ Age when first had sex with a female } & Control & 35 & 16.71 & 5.19 & 2.88 & $.009^{*}$ \\
\hline & BPD pathology & 19 & 8.26 & 12.23 & & \\
\hline
\end{tabular}

This article is protected by copyright. All rights reserved. 
Number of men had intercourse with

Number of men had oral sex with

\section{Past 12-months}

Number of men had intercourse with in last 12 months

Number of men had oral sex with in last

12 months

Length of time in current relationship (months)

$\begin{array}{lccccc}\text { Control } & 171 & 3.76 & 4.48 & -1.62 & .107 \\ \text { BPD pathology } & 38 & 5.13 & 5.71 & & \\ \text { Control } & 167 & .62 & 1.67 & -5.42 & <.0005^{*} \\ \text { BPD pathology } & 23 & 4.17 & 3.08 & & \end{array}$

Control

$170 \quad 1.26$

1.29

$-2.95 \quad .005^{*}$

BPD pathology $\quad 40 \quad 2.28$

2.08

Control

$48 \quad .17$

.429

$-4.17<.005^{\star}$

BPD pathology

20

2.30

2.27

Control

$48 \quad 1.56$

3.03

$-2.78 \quad .007^{*}$

BPD patholog 
$\mathrm{N}=254,{ }^{*}$ Bonferroni adjusted significant effect at $\alpha=0.01(0.05 / 5 ; 0.05 / 3)$. 
Table 2

Sexual coercion and sexual practices in female youth with borderline personality disorder pathology compared to controls.

\begin{tabular}{|c|c|c|c|c|c|c|}
\hline \multirow[t]{2}{*}{ Survey Item } & \multirow[t]{2}{*}{ Group } & \multirow[t]{2}{*}{$\mathrm{n}$} & Yes & No & \multirow[t]{2}{*}{$\mathrm{X}^{2}$} & \multirow[t]{2}{*}{$p$} \\
\hline & & & $\mathrm{N}(\%)$ & $\mathrm{N}(\%)$ & & \\
\hline \multicolumn{7}{|l|}{ Sexual Coercion } \\
\hline \multirow[t]{2}{*}{ Unwanted sexual experience } & Control & 98 & $28(28.6)$ & $70(71.4)$ & 4.09 & $.043^{*}$ \\
\hline & BPD pathology & 49 & $23(46.9)$ & $26(53.1)$ & & \\
\hline Being forced/frightened into doing & Control & 98 & $18(18.4)$ & $80(81.6)$ & 19.06 & $<.0005^{*}$ \\
\hline something sexually & BPD pathology & 49 & $27(55.1)$ & $22(44.9)$ & & \\
\hline
\end{tabular}

$\mathrm{N}=254,{ }^{*}$ Significant effect at $\alpha=0.05$. 
Table 3

General health factors in female youth with borderline personality disorder pathology compared to controls

\begin{tabular}{|c|c|c|c|c|c|c|}
\hline Survey Item & Group & $\mathrm{N}$ & Mean & SD & $\mathrm{t}$ & $\mathrm{p}$ \\
\hline \multirow[t]{2}{*}{ Health } & Control & 120 & 2.34 & .97 & -5.18 & $<.0005^{*}$ \\
\hline & BPD pathology & 50 & 3.20 & 1.03 & & \\
\hline \multirow[t]{2}{*}{ K6 Score } & Control & 120 & 6.63 & 4.24 & -6.48 & $<.0005^{*}$ \\
\hline & BPD pathology & 50 & 11.86 & 5.92 & & \\
\hline \multirow[t]{2}{*}{ Number of years smoked tobacco } & Control & 43 & 6.63 & 13.03 & 1.15 & .256 \\
\hline & BPD pathology & 29 & 3.81 & 2.66 & & \\
\hline \multirow{2}{*}{$\begin{array}{l}\text { Number of cigarettes smoked in a } \\
\text { day }\end{array}$} & Control & 37 & 1.81 & .74 & -5.55 & $<.0005^{*}$ \\
\hline & BPD pathology & 29 & 10.90 & 8.79 & & \\
\hline
\end{tabular}

This article is protected by copyright. All rights reserved. 
Frequency of drinking alcohol

$$
\begin{aligned}
& \text { Control } \\
& \text { BPD pathology }
\end{aligned}
$$

Control

BPD pathology

Control

BPD pathology

Control

BPD pathology

Age when first pregnant

Number Terminations
120

7.67

1.90

2.40

.018

$50 \quad 6.86$

2.23

102

3.79

2.60

$-3.06$

$.003^{*}$

46

46

5.85

4.21

$\begin{array}{lllll}19 & 17.95 & 2.78 & 1.12 & .271 \\ 12 & 16.83 & 2.56 & & \\ 19 & .74 & .73 & -1.82 & .081 \\ 7 & 1.29 & .49 & & \end{array}$

$\mathrm{N}=254,{ }^{*}$ Bonferroni adjusted significant effect at $\alpha=0.006(0.05 / 8)$; Health Score, lower score=better general health; K6 Score, higher score $=$ greater distress. 


\section{University Library}

\section{- M M N E R VA A gateway to Melbourne's research publications}

Minerva Access is the Institutional Repository of The University of Melbourne

Author/s:

Thompson, KN;Betts, J;Jovev, M;Nyathi, Y;McDougall, E;Chanen, AM

Title:

Sexuality and sexual health among female youth with borderline personality disorder pathology

Date:

2019-06-01

Citation:

Thompson, K. N., Betts, J., Jovev, M., Nyathi, Y., McDougall, E. \& Chanen, A. M. (2019). Sexuality and sexual health among female youth with borderline personality disorder pathology. EARLY INTERVENTION IN PSYCHIATRY, 13 (3), pp.502-508. https:// doi.org/10.1111/eip.12510.

Persistent Link:

http://hdl.handle.net/11343/293775 